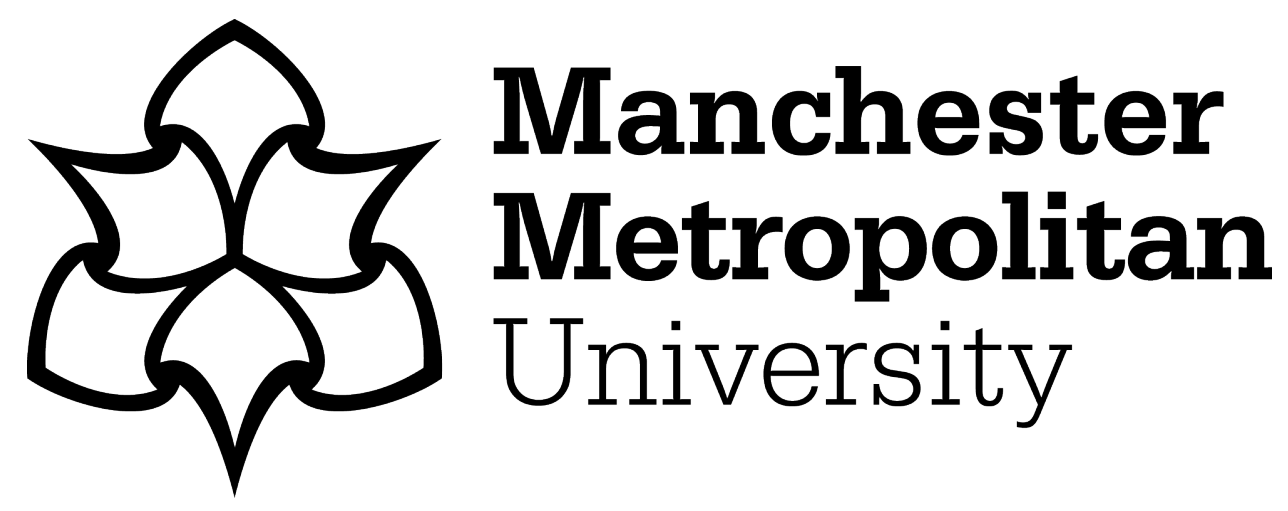

Strand, Bjorn Heine and Cooper, Rachel ORCID logoORCID: https://orcid.org/0000-0003-3370-5720 (2021) Monitoring changes in motor function in the years before death. BMJ: British Medical Journal, 374. n1882. ISSN 0959-535X

Downloaded from: https://e-space.mmu.ac.uk/628195/

Version: Accepted Version

Publisher: BMJ Publishing Group

DOI: https://doi.org/10.1136/bmj.n1882

Please cite the published version 


\section{Monitoring changes in motor function in the years before death}

Potential role for motor function in healthy ageing strategies

Bjørn Heine Strand, ${ }^{1} 3$ senior scientist, Rachel Cooper, ${ }^{4}$ professor of musculoskeletal epidemiology

${ }^{1}$ Department of Chronic Diseases and Ageing, Norwegian Institute of Public Health, Oslo, Norway

${ }^{2}$ Norwegian National Advisory Unit on Ageing and Health, Vestfold Hospital Trust, Tønsberg, Norway

${ }^{3}$ Department of Geriatric Medicine, Oslo University Hospital, Oslo, Norway

${ }^{4}$ Department of Sport and Exercise Sciences, Musculoskeletal Science and Sports Medicine Research Centre, Manchester Metropolitan University, Manchester, UK

Correspondence to: B H Strand bjornheine.strand@fhi.no

Research, doi:10.1136/bmj.n1743

Rises in life expectancy across the world since the mid-20th century, and resultant increases in the absolute number and proportion of the global population who are older, have been heralded as a major success of human endeavour. However, as Tedros Adhanom Ghebreyesus, Director-General of the World Health Organization, recently stated: "adding more years to life can be a mixed blessing if it is not accompanied by adding more life to years." The importance of identifying strategies to foster healthy ageing is thus increasingly recognised, exemplified by the United Nations proclaiming 2021-30 as the Decade of Healthy Ageing. ${ }^{2}$

Placing a spotlight on healthy ageing shifts the focus of public health strategies on ageing from disease oriented approaches to ones that consider a wider range of contributors to health and wellbeing including functional ability, intrinsic capacity and the environment. ${ }^{3}$ Objective measures of motor function, also commonly referred to as physical function or physical capability, are indicators of the person's intrinsic capacity, whereas self-reported measures include the environment and are indicators of functional ability and disability. So Landré and colleagues' linked paper (doi:10.1136/bmj.n1743) adds to a rapidly growing evidence base providing novel insights on healthy ageing. ${ }^{4}$

The authors analysed data from the Whitehall II study, a well known cohort study of British civil servants aged 35-55 years when recruited in the late 1980s. Between 2007 and 2016 more than six thousand participants with a mean age of 66 underwent motor function assessments on up to three occasions. Assessments included measures of walking speed, chair rise time, and grip strength, along with self-reported measures of functioning and difficulties with activities of daily living. Using linked data on all cause mortality, analyses aimed to 
characterise patterns of decline in these five measures of motor function in the years preceding death.

In the first set of analyses, the authors explored associations between each measure of motor function and subsequent rates of all cause mortality, using traditional time-to-event techniques. Here, their finding that poorer motor function was associated with increased rates of death confirms the already well established association between motor function and longevity. ${ }^{56}$ Most notably, it adds to findings from other recent studies showing that these associations are not confined to older populations, ${ }^{78}$ that both baseline levels and subsequent changes in motor function are associated with rates of death, ${ }^{910}$ and that using multiple measures of motor function provides added value. ${ }^{7}$

In the second, more novel, set of analyses, Landré and colleagues examined within person changes in motor function over 10 years, working backwards from time of death. This approach is commonly used in studies of cognitive function and dementia to explore accelerations in rates of cognitive decline in the final few years before death, a concept referred to as "terminal decline." ${ }^{11}$ However, these analyses are less commonly used in studies of motor function. ${ }^{12}$

The authors observed divergent patterns of within person change between participants who died and those who survived. Participants who died had poorer chair rise times than survivors up to 10 years before death, poorer self-reported functioning up to seven years before death, and more difficulties with activities of daily living up to four years before death. This ordering is consistent with the fact that performance based and self-reported measures of motor function complement each other to capture meaningful variation at different stages in the ageing and disablement processes.

Landré and colleagues rightly highlight the need to consider heterogeneity in ageing when interpreting their findings. However, their ability to investigate this heterogeneity was limited by the fact that less than one in 10 of their study sample died during follow-up, and no more than three measures of motor function were available for each participant. As the study participants continue to age and more data points accrue, looking in more detail at the different patterns of within person change in the years preceding death, what factors across the lifespan are associated with these differences, and whether these vary by cause of death will be illuminating. This additional information would be useful to inform the development of interventions to promote healthy ageing.

Although the authors suggest that "early detection of changes in motor function might offer opportunities for prevention and targeted interventions," what these interventions would 
be and what specifically they would be aiming to achieve is unclear. Despite the focus on death as an outcome in these analyses, our goal should always be to add life to years, not just years to life.

Competing interests: The BMJ has judged that there are no disqualifying financial ties to commercial companies. The authors declare no other competing interests.

The BMJ policy on financial interests is here:

https://www.bmj.com/sites/default/files/attachments/resources/2016/03/16-current-bmjeducation-coi-form.pdf

Provenance and peer review: Commissioned; not peer reviewed.

$<$ bok $>1 \quad$ World Health Organization. Decade of healthy ageing: baseline report. WHO, $2020 .<$ /bok $>$

$<$ eref $>2 \quad$ World Health Organization. UN Decade of Healthy Ageing. 2020 https://www.who.int/ageing/decade-of-healthy-ageing.</eref $>$

$<$ jrn $>3$ Beard JR, Officer A, de Carvalho IA, et al. The World report on ageing and health: a policy framework for healthy ageing. Lancet 2016;387:2145-54. PubMed doi:10.1016/S0140$\underline{6736(15) 00516-4</ j r n>}$

$<$ jrn $>4$ Landré B, Fayosse A, Ben Hassen C, et al. Terminal decline in objective and selfreported measures of motor function before death: 10 year follow up of Whitehall II cohort study. BMJ 2021;374:n1743.</jrn>

$<$ jrn>5 Cooper R, Kuh D, Hardy R; Mortality Review Group; FALCon and HALCyon Study Teams. Objectively measured physical capability levels and mortality: systematic review and meta-analysis. BMJ 2010;341:c4467. PubMed doi:10.1136/bmj.c4467</jrn>

$<$ jrn $>6$ Studenski S, Perera S, Patel K, et al. Gait speed and survival in older adults. JAMA 2011;305:50-8. PubMed doi:10.1001/jama.2010.1923 </jrn>

$<$ jrn $>7$ Cooper R, Strand BH, Hardy R, Patel KV, Kuh D. Physical capability in mid-life and survival over 13 years of follow-up: British birth cohort study. BMJ 2014;348:g2219.

PubMed doi:10.1136/bmj.g2219 $<$ jrn $>$

$<$ jrn $>8$ Strand $\mathrm{BH}$, Cooper R, Bergland A, et al. The association of grip strength from midlife onwards with all-cause and cause-specific mortality over 17 years of follow-up in the Tromsø Study. J Epidemiol Community Health 2016;70:1214-21. PubMed doi:10.1136/jech-2015$\underline{206776}</ \mathrm{jrn}>$

$<$ jrn $>9$ Sabia S, Dumurgier J, Tavernier B, Head J, Tzourio C, Elbaz A. Change in fast walking speed preceding death: results from a prospective longitudinal cohort study. $J$ Gerontol A Biol Sci Med Sci 2014;69:354-62. PubMed doi:10.1093/gerona/glt114</jrn> $<$ jrn $>10 \quad$ Syddall HE, Westbury LD, Dodds R, Dennison E, Cooper C, Sayer AA. Mortality in the Hertfordshire Ageing Study: association with level and loss of hand grip strength in later life. Age Ageing 2017;46:407-12. PubMed doi:10.1093/ageing/afw222</jrn> $<$ jrn $>11 \quad$ Karr JE, Graham RB, Hofer SM, Muniz-Terrera G. When does cognitive decline begin? A systematic review of change point studies on accelerated decline in cognitive and neurological outcomes preceding mild cognitive impairment, dementia, and death. Psychol Aging 2018;33:195-218. PubMed doi:10.1037/pag0000236</jrn> $<\mathrm{jrn}>12 \quad$ Xue QL, Bandeen-Roche K, Tian J, Kasper JD, Fried LP. Progression of physical frailty and the risk of all-cause mortality: Is there a point of no return? J Am Geriatr Soc 2021;69:908-15. PubMed doi:10.1111/jgs.16976 </jrn $>$ 